\title{
INTERNAL ROUND ROBIN TESTS FOR OPERATORS OF MECHANICAL TESTS
}

\author{
Bartosz Madejski \\ Institute of Aviation, Al. Krakowska 110/114, 02-256 Warsaw, Poland \\ bartosz.madejski@ilot.edu.pl
}

\begin{abstract}
For the characterisation of materials, the aeronautical industry accesses the expertise and the support of independent test laboratories. For the execution of characterisation tests of materials it is important that the test laboratory can fulfil the requirements of the testing expertly and continuously improves knowledge related to the tests. Quality systems are very helpful in this respect. One element of quality management systems is the internal round robin tests. This paper presents a procedure of teaching new operators to carry out tests. In addition, this article underlines how the importance of interlaboratory tests for finding and eliminating mistakes made by new operators. The analysis was performed for tensile tests. This test enables the assessment of operators and significantly improves the quality of tests.
\end{abstract}

Keywords: internal round robin tests, tensile tests, quality system, interlaboratory tests.

\section{INTRODUCTION}

Laboratories providing commercial services are obliged to possess certificates informing that tests performed are carried out according to the standards. In addition, most customers require undergoing numerous audits and achieving approvals under their supervision. Obtaining accreditation requires the involvement of additional financial resources and time. It is necessary to prepare a large number of procedures and laboratory equipment. In addition, it is important to undergo internal round robin tests and train the personnel (operators). Is it appropriate to involve additional resources in order to implement the quality systems? Yes, it is. Because we will not be able to earn much without customer approval, additional audits and improving our own qualifications as a laboratory.

The Materials and Structures Research Center (MSRC) keeps up with improvements in quality systems. Besides holding the accreditation of the Polish Centre of Accreditation (PCA) to perform mechanical tests, the MSRC must continuously meet the requirements for mechanical tests specified by its customers including General Electric (S-400) and Pratt \& Whitney. The most important issues during the accreditation process are internal round robin tests and training operators to carry out tests according to the standards. This paper focuses on exactly these two aspects as they are of crucial importance from the point of view of obtaining and maintaining accreditation.

\section{METHODOLOGY}

The most essential information for our customers is whether the results achieved in the laboratory fall within the limits acceptable by them, and whether the repeatability of results is in 
the range satisfactory for them. The goal of the internal round robin test is to guarantee reproducibility of tests and measurements carried out by different operators. An additional purpose of comparing results obtained in static tensile tests by different operators is to assess the skills of individual operators in order to verify which of them needs further training.

The material used for the tests was nickel alloy - INCONEL 718. Nickel alloys gained widespread use in gas turbines, jet engines, nuclear reactors, pumps and mechanical devices tooling because these alloys are characterized by corrosion resistance and high mechanical strength especially at high temperatures. That is precisely the reason why INCONEL 718 was chosen for the purposes of internal round robin tests.

Four operators carried out static tensile tests. Each of them had three specimens (Figure 1) machined in the same workshop with a raw bar with the same cast. All operators used the same machine in the tests.

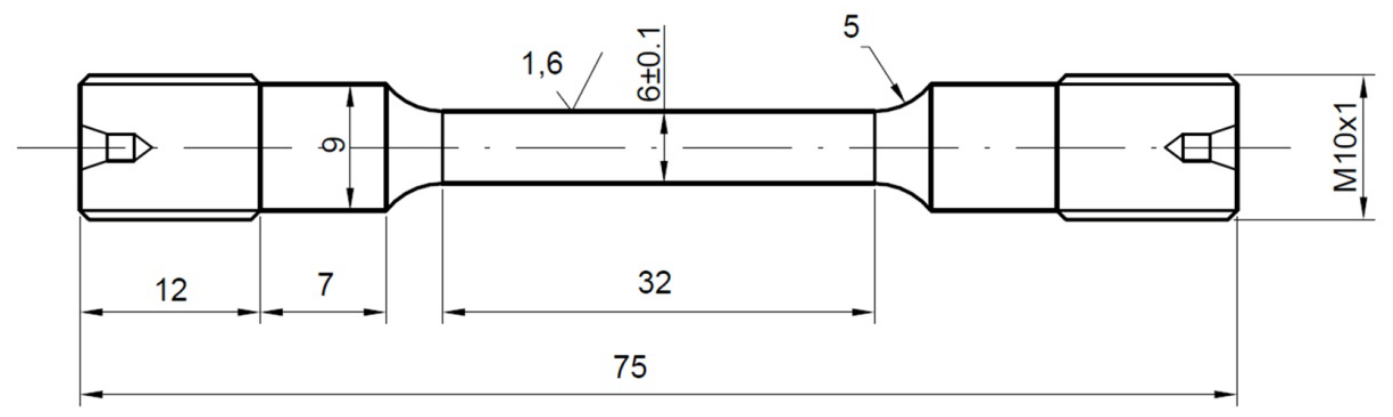

Figure 1. The specimen used in tensile tests (according ASTM E8)

Test conditions were the same for all the participants (Table 1). When internal round robin tests are performed it is important to remember to carry out tests on the specimens made of the same raw bar with the same cast. Additionally, the same machines should be used to avoid differences in results.

Table 1. Test Conditions for static tensile test (according ASTM E8)

\begin{tabular}{|c|c|}
\hline Temperature of the tests & $\sim 22-25\left[{ }^{\circ} \mathrm{C}\right]$ \\
\hline \multicolumn{2}{|c|}{ Speed of the tests } \\
\hline First Speed & $0,1 \mathrm{~mm} / \mathrm{min}$ \\
\hline Secondary Speed & $1,5 \mathrm{~mm} / \mathrm{min}$ \\
\hline Removal Point & $1,5 \%$ \\
\hline
\end{tabular}

It is usually two out of four operators who carry out static tensile tests (operators III and IV). The other two are trained to carry out tensile tests. In order to verify the correctness of training and meet the customer's demands we have to perform internal round robin tests. Each operator has to estimate the following parameters: Young's Modulus $(E)$, elastic limit $\left(R_{0,02}\right)$, yield strength $\left(R_{0,2}\right)$, ultimate tensile strength (UTS), elongation (A4), and reduction of area (RoA).

\section{RESULTS AND DISCUSSION}

After each test the results are analyzed. The analysis process consists of two steps:

Step 1: The data analysis of the individual participant

For each characteristic (for every operator) of the tests performed the mean value and standard deviation. 
Step 2: Analysis of the means

Using the mean values obtained for every operator, the initialization of the analysis is made:

$$
\begin{gathered}
\dot{X}=\sum \frac{\dot{x}}{p} \\
\dot{X}-\text { robust mean } \\
\dot{X}_{l}-\text { mean of each operator }
\end{gathered}
$$$$
\dot{S D}=1.134 \sqrt{\sum \frac{\left(\dot{x}_{l}-\dot{x}\right)^{2}}{(p-1)}}
$$

p- number of operators

$\dot{S D}$ - robust standard deviations

The data obtained from the robust analysis is evaluated and classified against the following criteria:

$>$ Class 1: robust mean \pm 1 robust Standard Deviation

$>$ Class 2: robust mean \pm 2 robust Standard Deviation

$>$ Class 3: robust mean $>2$ robust Standard Deviation

Step 3: Analysis of all standard deviations

The standard deviation is calculated in accordance with the ISO 5725-2 standard. The data obtained is evaluated and classified against the following criteria:

$>$ Class 1: 0 to 1 variance repeatability

$>$ Class 2: 1 to 2 variance repeatability

$>$ Class 3: $>2$ variance repeatability

The value for the student's t distribution was chosen based on the level of significance of 0,3 (acceptable probability of error) and the number of degrees of freedom equals 6 [2, 3].

The calculations gave the mean results of each mechanical parameter within the standard deviation for each operator (Table 2). The results obtained by the operators I and II (new operators) went beyond class 3 (for yield strength and ultimate tensile strength). Unfortunately, the results should be in the range between class 1 and 2, so class 3 is not acceptable. For operators who usually do this study (operators III and IV), all the results are in class 1 or 2 (so these are acceptable results).

Table2. The results from static tensile tests for all operators

\begin{tabular}{|l|c|c|c|c|c|c|}
\hline \multirow{2}{*}{ Operator } & \multicolumn{2}{|c|}{$\begin{array}{c}\text { YoungaModulus } \\
{[\mathrm{GPa}]}\end{array}$} & \multicolumn{2}{c|}{$\begin{array}{c}\text { Elastic limit (0,02\%) } \\
{[\mathrm{MPa}]}\end{array}$} & \multicolumn{2}{c|}{ Yieldstrength(0,2\%) [MPa] } \\
\hline & mean & SD & mean & SD & mean & SD \\
\hline I operator & 178,3 & 2,9 & 398,5 & 9,3 & 504,4 & 11,3 \\
\hline II operator & 193,4 & 2,1 & 374,1 & 6,1 & 506,4 & 7,6 \\
\hline III operator & 188,3 & 1,1 & 379,9 & 2,8 & 505,2 & 2,6 \\
\hline IV operator & 186,3 & 4,5 & 382,5 & 6,2 & 499,3 & 0,9 \\
\hline
\end{tabular}

\begin{tabular}{|l|c|c|c|c|c|c|}
\hline \multirow{2}{*}{ Operator } & \multicolumn{2}{|c|}{$\begin{array}{c}\text { Ultimate } \\
\text { tensilestrength[MPa] }\end{array}$} & \multicolumn{2}{c|}{ Elongation A5 [\%] } & \multicolumn{2}{c|}{ Reduction of area [\%] } \\
\hline & mean & SD & mean & SD & mean & SD \\
\hline I operator & 872,8 & 14,4 & 54,2 & 3,3 & 66,3 & 1,4 \\
\hline II operator & 877,3 & 9,1 & 52,2 & 0,9 & 65,9 & 0,5 \\
\hline III operator & 873,7 & 2,3 & 52,4 & 0,5 & 65,8 & 0,1 \\
\hline IV operator & 864,1 & 5,9 & 53,0 & 0,7 & 66,0 & 0,4 \\
\hline
\end{tabular}
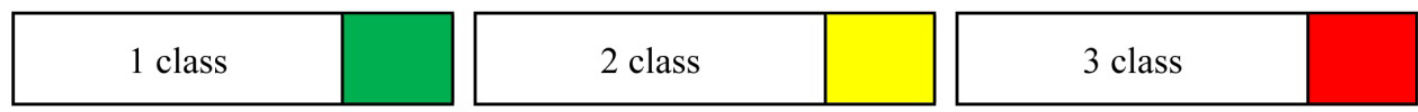
The range of class for the mean value and repeatability for each mechanical parameters were estimated (Table 3).

Table 3. The mean results and repeatability for each mechanical parameter for tensile tests

\begin{tabular}{|c|c|c|c|c|c|c|c|c|c|c|c|c|}
\hline \multicolumn{13}{|c|}{ Mean value } \\
\hline & \multicolumn{2}{|c|}{$\mathrm{E}$ [GPa] } & \multicolumn{2}{|c|}{$\mathrm{R}_{0,02}[\mathrm{MPa}]$} & \multicolumn{2}{|c|}{$\mathrm{R}_{0,2}[\mathrm{MPa}]$} & \multicolumn{2}{|c|}{ UTS [MPa] } & \multicolumn{2}{|c|}{ A5 [\%] } & \multicolumn{2}{|c|}{ RoA [\%] } \\
\hline 1 class & 179,3 & 193,5 & 372,3 & 395,9 & 500,1 & 507,3 & 865,4 & 878,2 & 51,9 & 53,9 & 65,7 & 66,2 \\
\hline 2 class & 172,2 & 200,6 & 360,5 & 407,7 & 496,5 & 510,8 & 859,0 & 884,6 & 50,9 & 54,9 & 63,9 & 66,5 \\
\hline \multicolumn{13}{|c|}{ Repeatability } \\
\hline & \multicolumn{2}{|c|}{$\mathrm{E}[\mathrm{GPa}]$} & \multicolumn{2}{|c|}{$\mathrm{R}_{0,02}[\mathrm{MPa}]$} & \multicolumn{2}{|c|}{$\mathrm{R}_{0,2}[\mathrm{MPa}]$} & \multicolumn{2}{|c|}{\begin{tabular}{|l|} 
UTS $[\mathrm{MPa}]$ \\
\end{tabular}} & \multicolumn{2}{|c|}{ A5 [\%] } & \multicolumn{2}{|c|}{ RoA [\%] } \\
\hline 1 class & 0,0 & 7,1 & $\overline{0,0}$ & 11,8 & $\overline{0,0}$ & 3,6 & 0,0 & 6,4 & 0,0 & 1,0 & 0,0 & 0,3 \\
\hline 2 class & 7,1 & 14,2 & 11,8 & 23,6 & 3,6 & 7,2 & 6,4 & 12,8 & 1,0 & 2,0 & 0,3 & 0,5 \\
\hline
\end{tabular}

The results included in Tables 2 and 3 are presented using the graphs where ranges of class for the mean value and repeatability are marked. In Figure 2 you can see that Young Modulus for two operators (new operators) are between class 1 and 2.

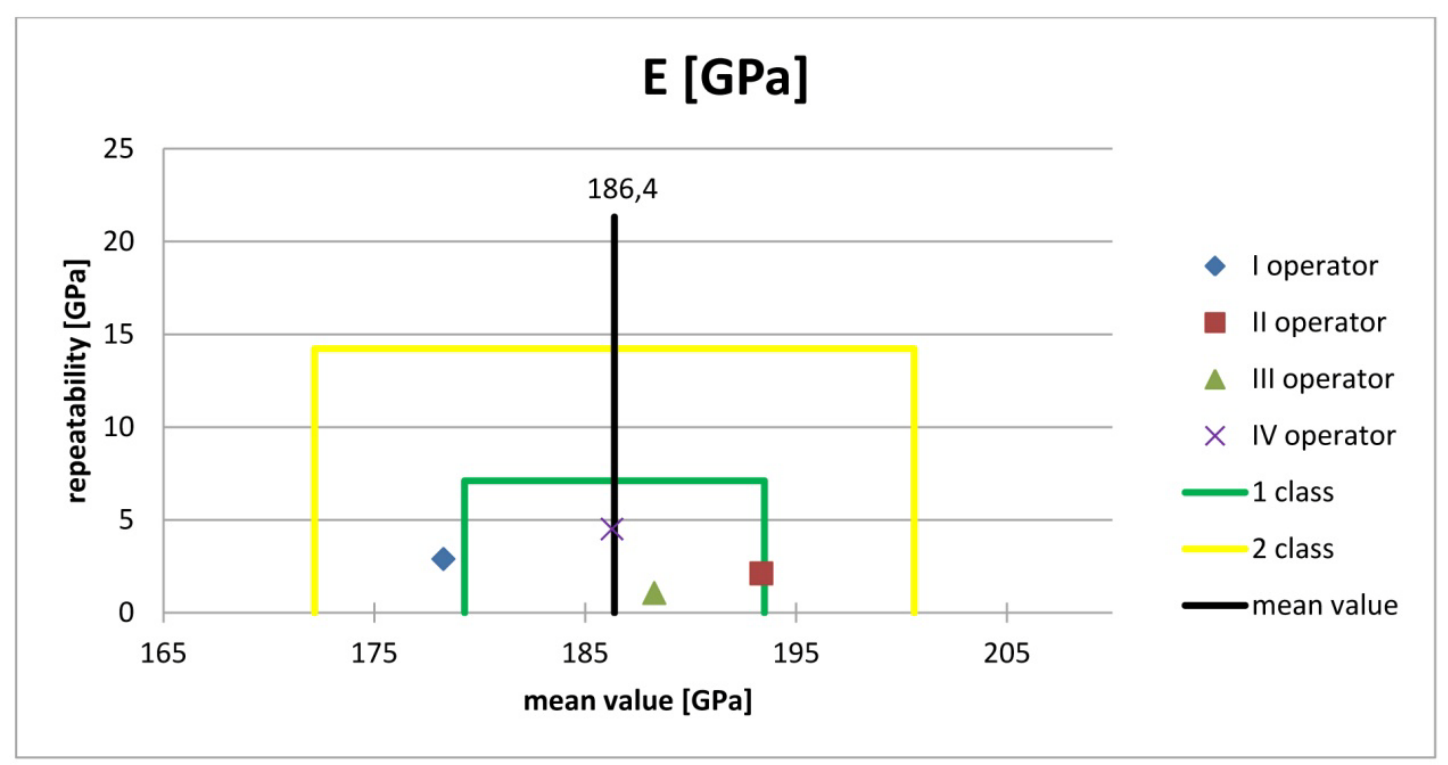

Figure 2. The results for Young Modulus

It is very important to estimate Young Modulus correctly. If this parameter is estimated incorrectly, it will affect Yield Strength and Elastic Limit. The effect of incorrectly estimated Young Modulus can be seen in the graphs bellow. Incorrectly estimated Young Modulus caused further mistakes for Elastic Limit (Figure 3) and Yield Strength (Figure 4). 


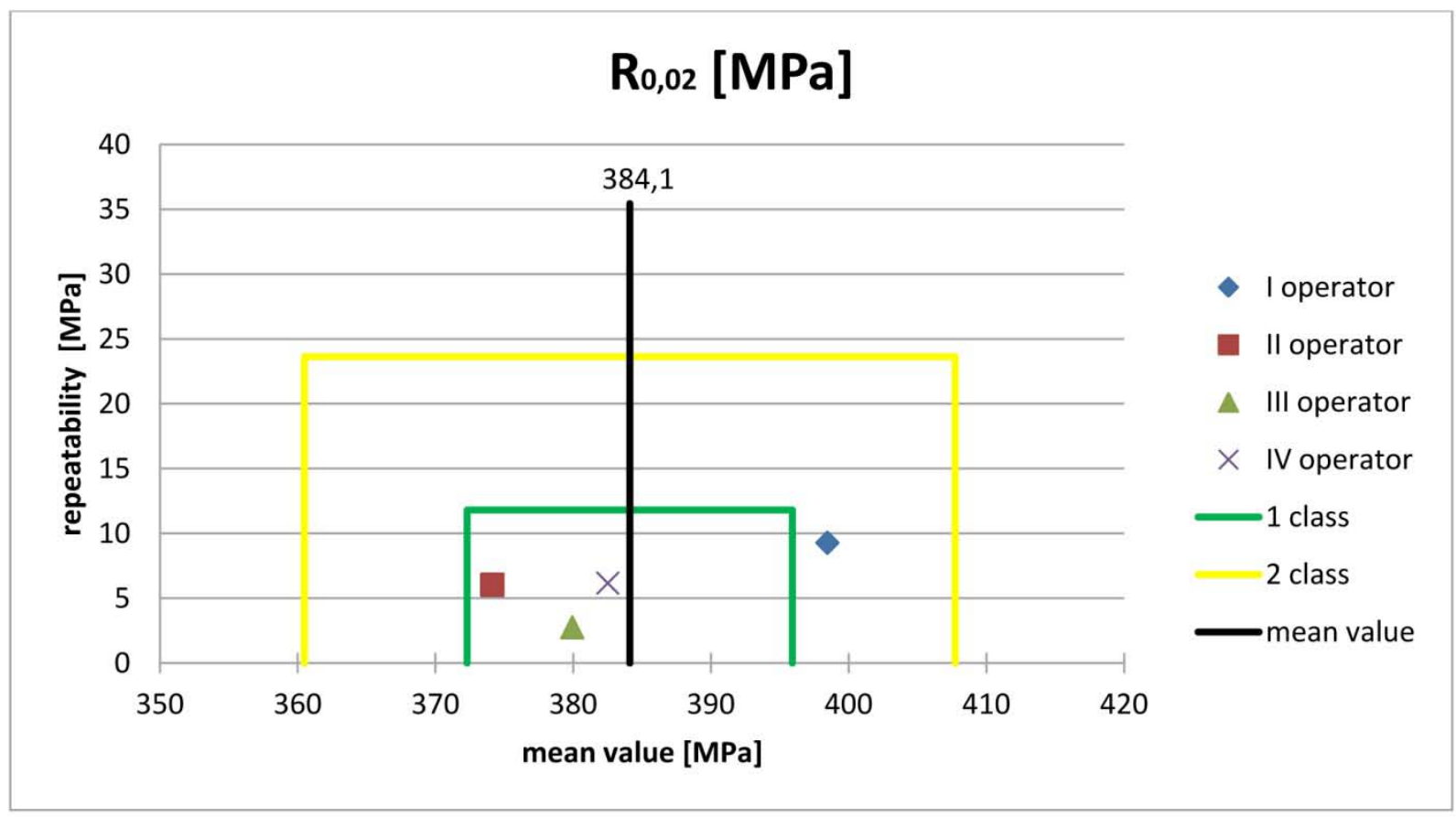

Figure 3. The results for Elastic Limit

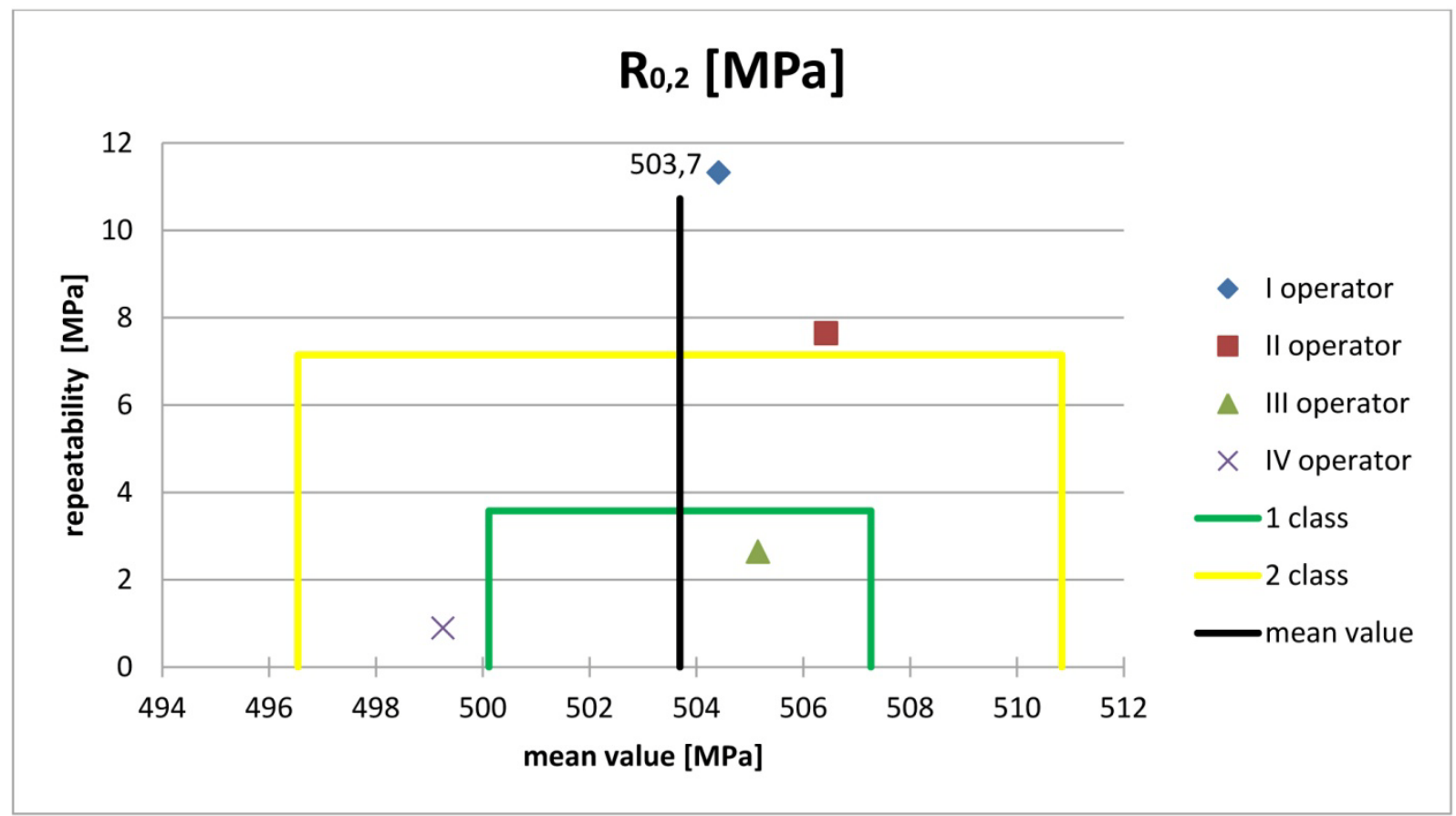

Figure 4. The results for Yield Strength

The operator has the least impact on the results of Ultimate Tensile Strength (UTS) so the mean value and repeatability should be similar for all operators. Unfortunately, the study shows that for the UTS parameter there are significant differences between participants (Figure 5). More importantly, only one operator achieved class 1 for the mean value and repeatability. This could have been caused by the wrong installation of the specimens or some other mistakes in performing the tests. 


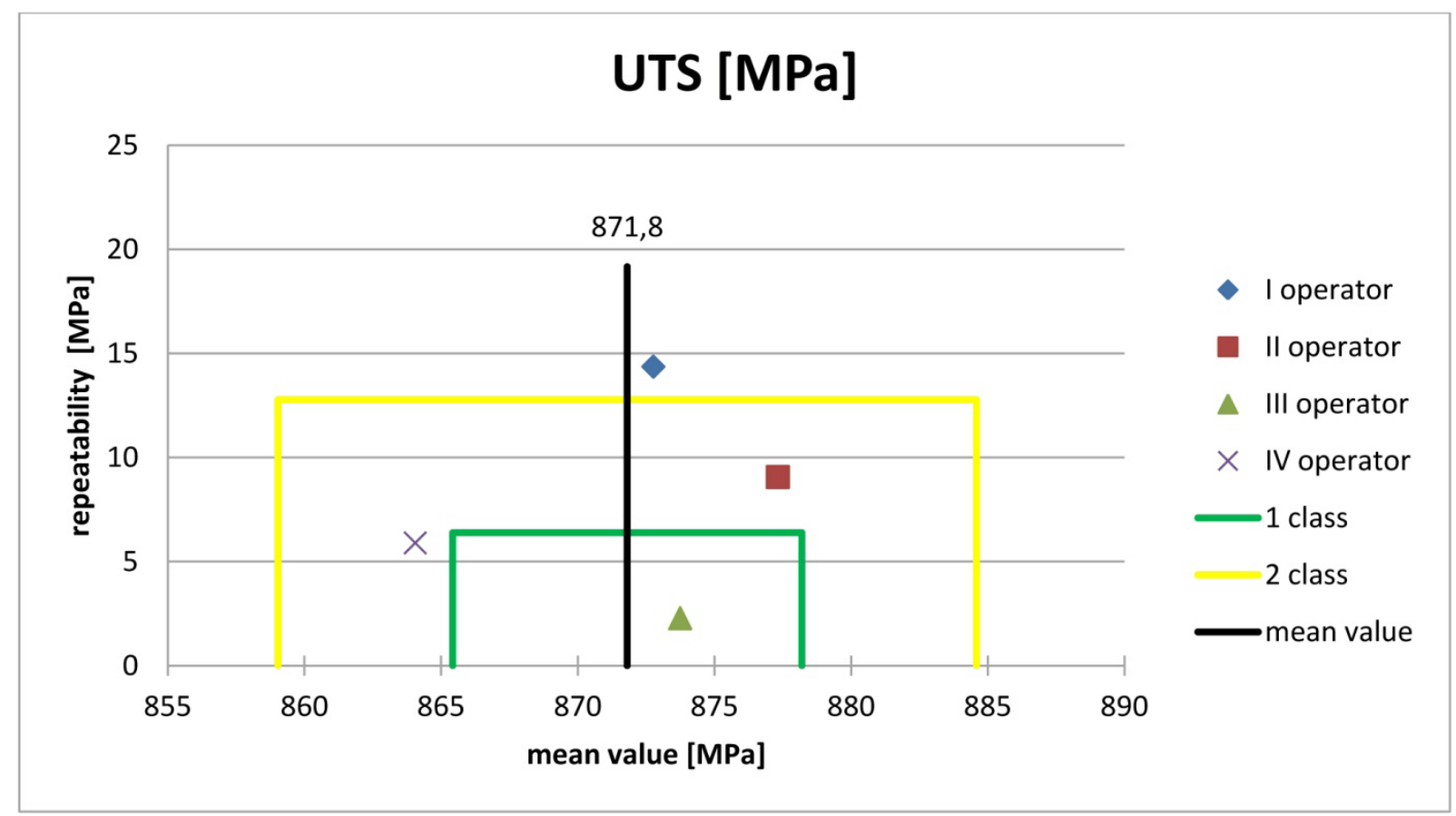

Figure 5. The results for Ultimate Tensile Strength

The results of elongation (A5 - Figure 6) and reduction of area (RoA - Figure 7) are very good for three operators. The mean value for elongation reduction of area are in class 1 . Only for one operator the mean value and repeatability for elongation and reduction of area are in class 3 . It is likely to have been caused by the operator's lack of experience with a digital projector, especially with measuring specimens before and after tensile tests.

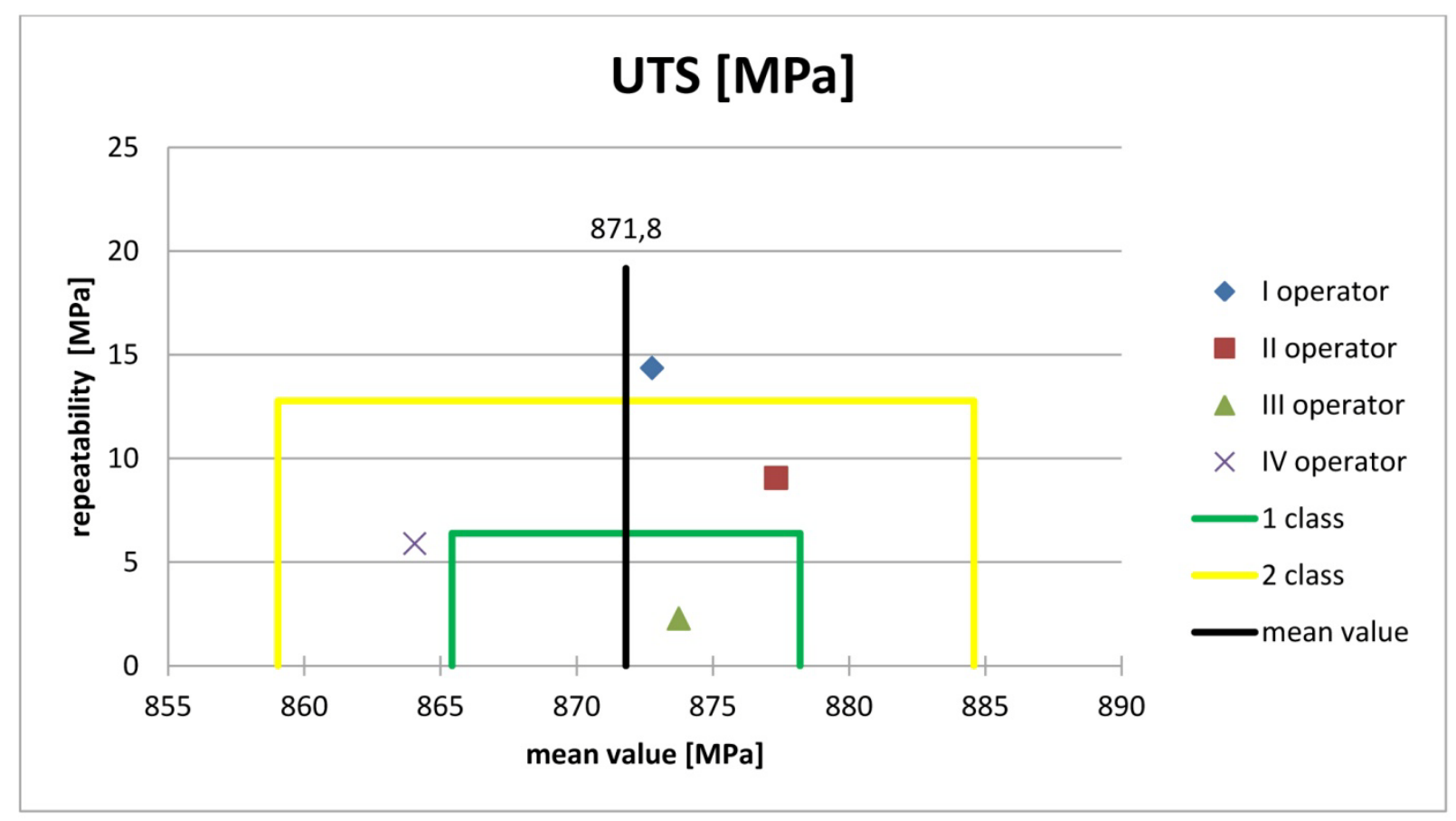

Figure 6. The results for elongation - A5 


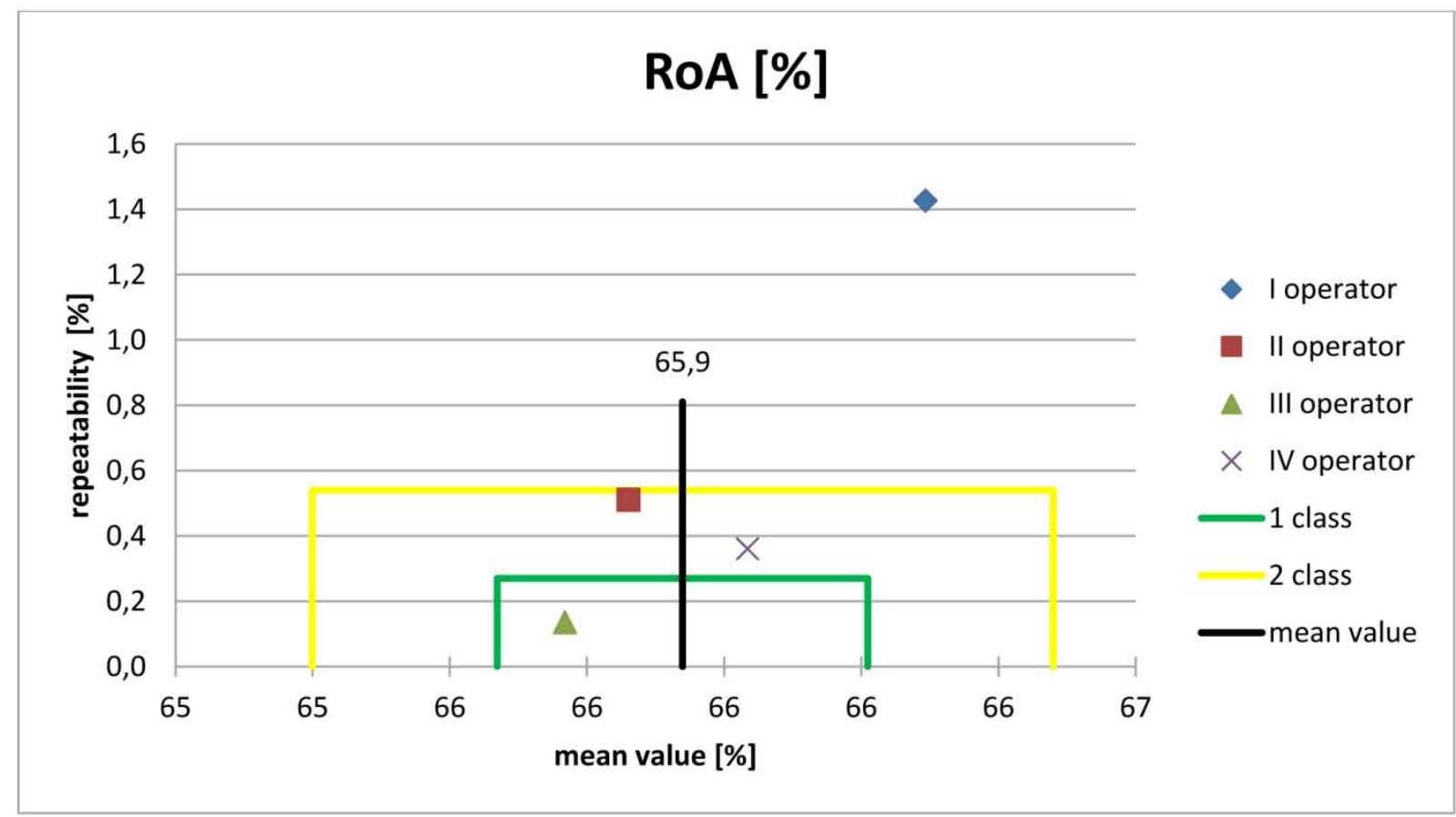

Figure 7. The results for reduction of area - RoA

The operator who achieved all results in class 1 (operator III) made recalculation of Young Modulus for all specimens. He did it in order to define the influence of the incorrect calculation of Young Modulus on Yield Strength and Elastic Limit. New results are shown in Figures 8, 9 and 10. After recalculation, Young Modulus and Yield Strength obtained by two new operators are considerably better. The mean values achieved class 1 (see red arrows Figure 8 and 9). In the case of the operator who usually performs tensile tests (operator IV), very similar results (blue circle) could be observed. It means that he calculated this parameter correctly.

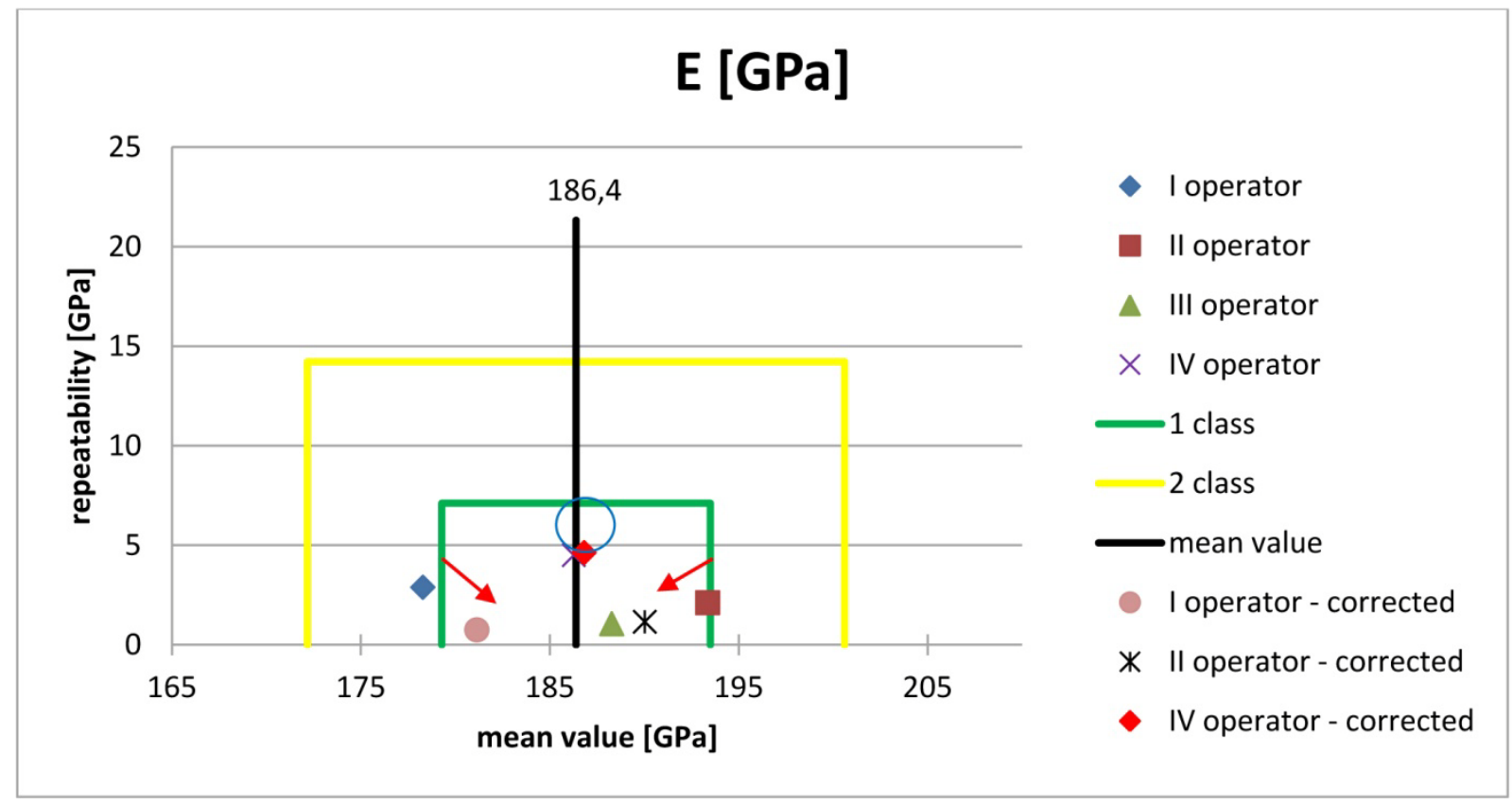

Figure 8. The results for Young Modulus after recalculation 


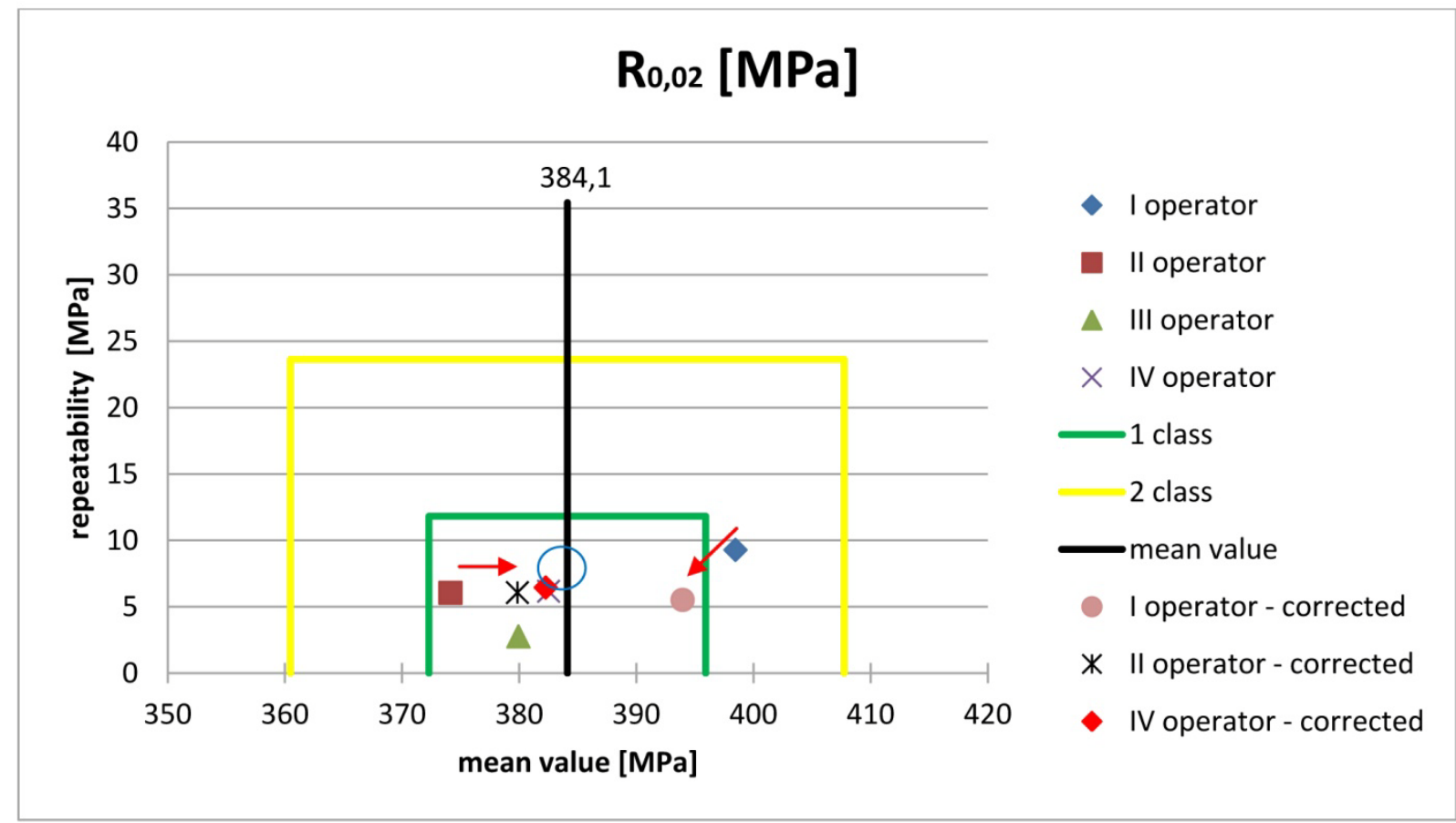

Figure 9. The results for Elastic Limit after recalculation

The results for Yield Strength did not change significantly after recalculation. In this case, the recalculation of Young Modulus did not affect Yield Strength. The points in the graphs (Figure 10) are in the same places. It means that incorrect results (obtained by new operators) were not caused only by incorrect Young Modulus. The analysis of the results obtained by the trainees showed additional mistakes they made. First of all, these were the mistakes during the mounting of specimens on the machine. Secondly, the preparation of specimens for the tests was incorrect.

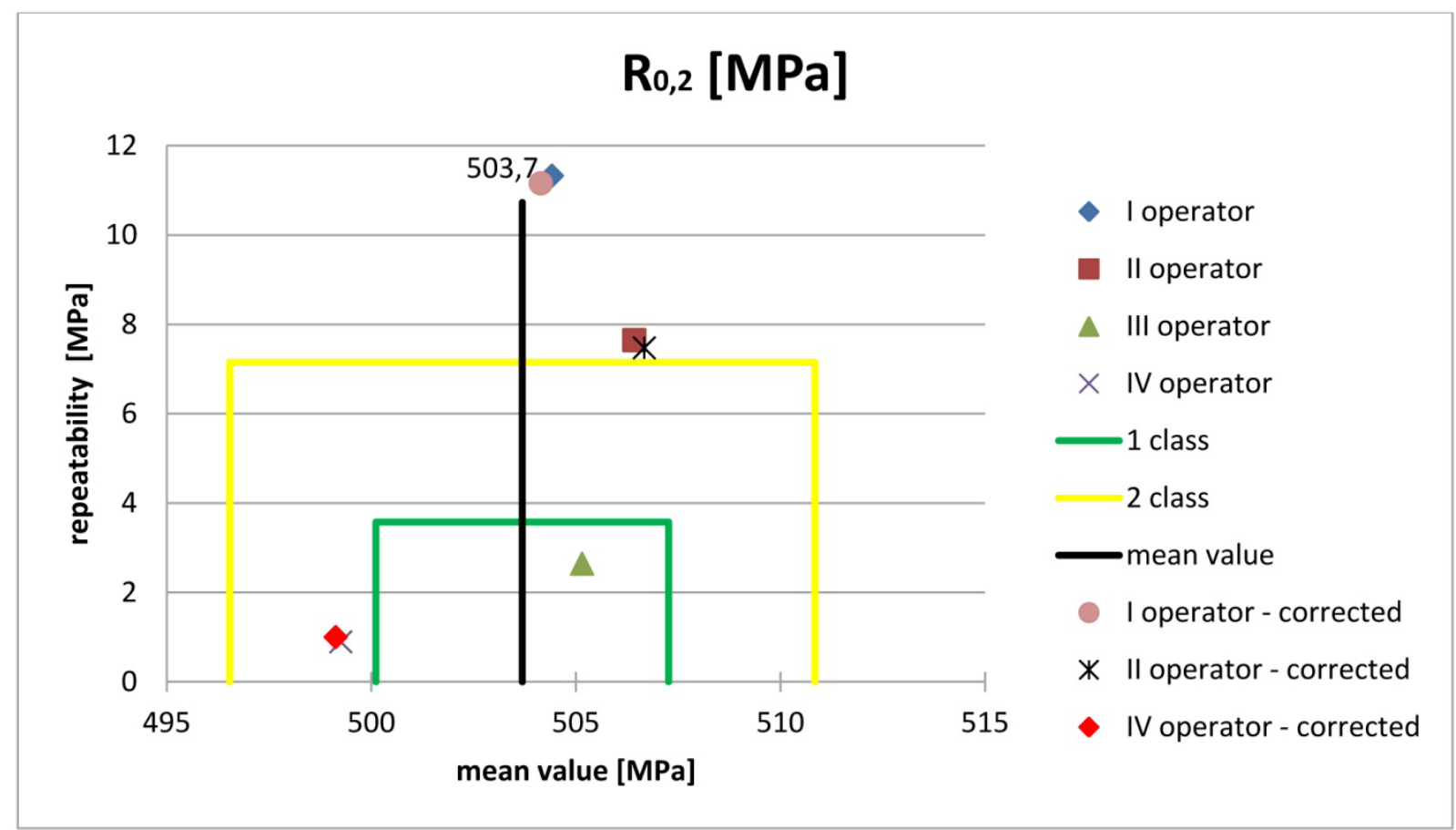

Figure 10. The results for Yield Strength after recalculation 
Factors affecting the final result of the static tensile test defined by the internal round robin test are as follows:

$>$ wrongly fit extensometer can affect Young Modulus, Yield Strength and Elastic Limit results;

$>$ it is very important to estimate Young Modulus correctly because mistakes in Young Modulus cause misleading results for Yield Strength and Elastic Limit;

$>$ incorrect mounting can cause wrong results (it is very important to eliminate free space in the gripping part to fit the specimens and to make corrections during the mounting);

$>$ measurement of the specimens before and after the tests (if it is incorrectly performed wrong results can be received).

Summing up: although the tensile test is a very simple test, its results can be affected by a number of factors. This fact is often overlooked during training new operators.

\section{SUMMARY}

The internal round robin test conducted enabled defining the parameters which can affect the results of static tensile tests. Furthermore, it proved the importance of these tests for the test quality improvement.

It is recommended that:

$>$ Additional training in correct estimation of Young Modulus be carried out ;

$>$ In-depth analysis of preparation and mounting specimens on the machine be carried out to define mistakes which can affect test results (especially the UTS parameter);

$>$ Additional training concerning the preparation and measurement of the specimens be carried out.

Defining errors in tensile tests and other types of tests can help to improve the quality of tests. This can also help to achieve approval for mechanical tests.

\section{REFERENCES}

[1] ASTM E8E8M-15 - Standard Test Methods for Tension Testing of Metallic Materials.

[2] E691 Standard Practice for Conducting an Interlaboratory Study to Determine the Precision of a Test Method.

[3] ISO 5725-2 standard. 